It will be noticed also that $D, F, A$ generate $\frac{B b}{16}$, or red, yellow, blue generate indigo:blue. A, C, E generate $\frac{\mathrm{F}}{\mathrm{I} 6}$, or blue, violet, orange generate yellow. I need not increase the length of my paper by more examples, but leave the field open- to all who choose to test the above formula as regards its application to combinations of colour.

In conclusion, I wish to make the following suggestion.

Should it be admitted that the musical scale, in its perfect division into intervals uncler the law of harmonical progression, finds its counterpart in Newton's rings. rather than in the prismatic spectrum, would not a spectroscope, constructed so as to give the image of these rings, be a more perfect instrument for the comparison of colours than that in present use? We might also have a double spectroscope, capable of giving the images of the secondary rings produced by the refraction of homogeneous light, the cube roots of whose diameters give the series which corresponds to that of the musical scale.

We should in this way be able to know the melody which corresponds to the light of any particular star, provided that the light be strong enough to produce the images of the secondary rings.

Rome, February 18

W. S. OKELY

\section{Analogy of Colour and Music}

AT the close of my short article on the Analogy of Colour and Music, published in your journal of January I 3 , I ventured to ask for the opinion of physicists on the subject. Accordingly $\mathbb{I}$, for one, am much indebted to the many able contributors who thereupon addressed you. The correspondence having apparently ceased, I will now ask your permission to say a few words.

Although I do not attach too much importance to the closely approximate ratios, given in my paper, between the wavelengths of colour and the notes of the diatonic scale, yet I think nothing said by your correspondents seriously affects my main argument.

The most important objection is that urged by Mr. Monro (NATURE, No. I4), who regards the correspondence of the two ratios as a mere coincidence, depending on the mode by which Prof. Listing obtained his scale of wave-lengths of the colours. By an ingenious calculation, Mr. Monro shows that Listing most probably" divided his spectrum into seven equal parts upon some scale which varies inversely as the wave-lengths ; . . . so that it nearly corresponds with the ratios of the musical scale because these approximately form a harmonic progression." When I wrote my article I had not read Listing's paper, but, as stated, quoted his numbers from a recent memoir by Thalen. The perusal of his original paper shows me that Listing obtained his numbers in the following manner, which I think Mr. Monro will see confirms his calculation, but overrides his criticism:-

Employing pure spectra, and using every precaution, Listing experimentally determines the transition places and the central region of each colour, Fraunhofer's lines being used as landmarks. The observations are repeated upon the normal spectrum obtained by diffraction, and are checked by the independent observations of others, and by repetitions at different times. In this way the remarkable fact is disclosed that the numbers of vibrations at the transition spots form an arithmetical progression throughout the entire series of colours. For reasons given he adopts the following scale of colours-brown, red, orange, yellow, green, cyanogen, indigo, and lavender, and states as a law that this series can be physically expressed by an arithmetical pro. gression of eight numbers, in which the last is the double of the first. He then proceeds to discover the constant factor by which this series can be turned into absolute values. After considerable care, and upon grounds fully detailed, he selects $48 \frac{1}{2}$ billions as the number of vibrations per second expressing the range of each colour. The possible error he shows to be \pm 0.038 -taking billions as unity-and this, though apparently a large error, is actually less than $\frac{\lambda}{7}$ th of the interval between the two $D$ lines.

The number of vibrations corresponding to the extreme limit of colour at the red end, he fixes, upon Helmholtz's and Angstrom's authority, at $363^{\circ} 9$ billions per second, or a wave-length of 819.8 millionths of a millimetre. By adding to the former number half the colour interval-namely, $24 \frac{1}{4}$ billions-the normal centre of the first colour is obtained; $48 \frac{1}{2}$ billions added to that gives the centre of the next colour, and so on. These, and also the limits of each colour, are tabulated along with the corresponding wave-lengths.

Listing closes his paper with the statement of a general law, that while the successive vibrations of the series of colours in the spectrum form an arithmetical progression, the same is also true of the logarithms of the vibrations corresponding to each musical note in the so-called chromatic scale. Hence he concludes that although physiologically and pyschologically there may be differences, yet there is an indisputable physical basis for the analogy between tones and colours. From this very imperfect outline it will be seen that the entire memoir is a remarkable one, and I am surprised no translation of it has appeared. It is certainly the most important contribution to the analogy that I have met with, and renders my little paper on the subject quite unnecessary.

Mr. Okely, writing to the next number of NATURE, gives some additional evidence in favour of the analogy, but thinks my process of taking the nean of the limiting wave-lengths of each colour, in order to obtain the average wave-length, is "very rough." Mr. Okely does not tell us what he would do in such a case, but turns aside to become the champion of the wirlths of Newton's rings, charging me with having treated too summarily this old and famous ally of the analogy. But to this, my next critic, Mr. Sedley Taylor, replies, although other considerations also influenced me in neglecting this analogy.

Mr. Taylor, however, believes that he has deprived my comparison of any serious importance, for the following reason:In the musical scale, he observes, "a very slight departure from accurate pitch in any concord provoles a harsh dissonance;" but "any part of any one colour-division produces an equally harmonious effect on the eye," because "in the spectrum there is very little, if any, change of tint except close to the extremities of any one colour." Whilst it would be certainly unwise to push the analogy too far, I think Mr. Taylor is here mistaken. There is a very material difference of tint in different parts of any one colour in the spectrum. Regarded alone, any region of the spectrum, like any single musical note, is, of course, equally agreeable; but it is not the case that an equally harmonions effect on the eye is produced by the combination of any part of any one colour-division with some other colour.

Mr. Stuart, in an interesting letter, points out a close relationship, discovered by Prof. Mossotti, between the intensities of the light in different parts of a normal spectrum and the notes of the diatonic scale. Finally, Dr. Chaumont, in an early part of this discussion, showed, what indeed had been noticed elsewhere, that if the ratios I give be accepted, then the once-called primary colours, red, yellow, and blue, correspond to the notes of the common chord ; whilst the modern triad, red, green, and blue, correspond to the tonic, sub-dominant and dominant, that is to say, to the three notes which in music constitute the fundamental base of the scale.

In addition to what has been brought forward in this correspondence, there are some valuable remarks on the analogy in one of Dr. "Thomas Young's memoirs, "Philosophical Transactions, 1802"; in Chevreul's work on the "Principles of Harmony of Colour" ; in a recent brochure by Dr. Macdonald on "Sound and Colour"; and, lastly and chiefly, in \$19 of Helmholtz's "Physiological Optics." In this last a list is given of authorities who have written on the subject since the time of Newton.

Reviewing what has been done in this matter, there are therefore, I believe, many good grounds for asserting the existence of a physical basis for the analogy between colour and tone. Opposed, it. is true, are many mental differences: such, for example, as that of the judgment, which is far more prompt and correct in determining a colour than a note; then also colour primarily involves only the conception of space, music the conception of time. Nevertheless against all this we may place the facts that the source of harmony in colour, as in music, is purely a question of relative impressions ; and a painting and a melody evoke a succession of ideas that have a remarkable similarity,

Woodlands, Isleworth, March I3

W. F. BARRETT

\section{THE METROPOLITAN MAIN DRATNAGE}

$T H E$ magnitude of the underground works of London is scarcely understood by the public in general. They occasionally hear of this or that sewer or pumping station being completed, but as the greater portion of 
them is hidden beneath the surface of the ground, nothing but a personal inspection during the piocess of construction can give any adequate idea of the vastness and intricacy of our drainage system. The following facts, collected from the engineer's papers on the subject and reports to the Metropolitan Board of Works, may present to the mind some notion of these great works. There are about 1,400 miles of sewers in London, 82 miles of which are intercepting sewers of "The Main Drainage." The area drained by the intercepting sewers is about roo square miles. The total amount of sewage and rainfall which they will carry off is 63 million cubic feet per day, or equal to a lake as large as Hyde Park four feet in depth. There have been consumed in their construction about 340 million bricks, and upwards of 900,000 cubic yards of concrete. The total engine-power employed is 2,380 nominal horse-power, but this will soon be increased by about 400 horse-power on the construction of the Pimlico pumping station. The cost of these works when completed will be a little over $4,000,000 l$.

The accompanying map shows the position of the main intercepting sewers, pumping stations, outfalls, \&c., and this being that the main sewers in existence before the construction of the main drainage, emptied themselves into the Thames, running more or less at right angles to it, and consequently, by constructing the intercepting sewers parallel to it, they would cross all the main outlets and cut off their sewage. In carrying out this scheme the great object to be kept in view was to discharge as much sewage as possible by gravitation, in order to avoid the great expense of pumping. To this end three lines of sewers are constructed on each side of the Thames, called respectively the High, Middle, and Low Level sewers, together with their branches. On the north side the High and Middle Level discharge their sewage by gravitation; that of the Low Level, which joins them at Abbey Mills, being pumped up a height of 36 feet into the Upper Level, when all three flow through the Northern Outfall Sewer to the reservoirs at Barking, and discharge their contents into the river by gravitation. On the south side the Low Level sewer meets the High and Middle Level at Deptford, where its contents are pumped a height of 18 feet into the Outfall Sewer, which carries the three streams to Crossness, where they can discharge by gravitation; but as this can only be done at low water, they are generally pumped a height of 20 feet into the reservoirs. Such is the general outline of the Main Drainage scheme, as being carried out by Mr. Bazalgetté, the able engineer of the Metropolitan Board of Works.

Before commencing these works a large number of experiments and observations had to be made in ofder to decide the numerous knotty points that suggested themselves: such as the determination of the position of the outfalls, the shape and inclination of the sewers, the amount of sewage and rainfall to be provided for, the amount to be pumped, \&c., \&c., each requiring a great amount of labour and study. The results arrived at, and which were acted upon, may be summed up as follows :-That it was necessary to take the sewage down the river as far as Barking Creek; that its lowest mean velocity should be $I_{2}^{\frac{1}{2}}$ miles per hour; the quantity of sewage to be intercepted was, in populous districts, 750,000 gallons per square mile per day; the amount of rainfall to be provided for was a quarter of an inch per day; the form of the sewers was to be circular, and the sewage was to be discharged at or about the time of high water. The above are a few of the principles upon which the Main Drainage of London is based.

THEWORKS. - The High Lever Sewer North commences near Hampstead Hill, where it intercepts the Fleet Sewer. It varies in size from $4 \mathrm{ft}$. in diameter to $9 \mathrm{ft}$. $6 \mathrm{in}$. by I $2 \mathrm{ft}$, is about seven miles long, and drains an area of about ten square miles in its course from Hampstead to its junction with the Middle Level at Old Ford. It passes under three railways, the New River, and Sir George Duckett's Canal, in the lasi case the top of the sever is within $2 \mathrm{ft}$. of the waters in the canal.

The Middle Level Sewer commences near Kensal Green and flows to its junction with the High Level at Old Ford. The total length of the main line, together with the Piccadilly branch, is about $11 \frac{7}{2}$ miles; the area drained is $17 \frac{1}{2}$ square miles; in form it varies from $4 \mathrm{ft}$. $6 \mathrm{in}$. by $3 \mathrm{ft}$. to $\mathrm{gft}$. $6 \mathrm{in}$. by $\mathrm{I} 2 \mathrm{ft}$. Six miles of this sewer were constructed in tunnel. In its course it passes under two canals and one railway, and over the Metropolitan line, across which it was carried without interfering with the traffic, the bottom of the sewer being only a few inches above the chimneys of the engines.

At the junction of the High and Middle Level sewers there is a large "penstock" and "weir" chamber, for the purpose (should occasion demand) of letting storm waters or all the sewage flow into the River Lea. It is I 5 oft. in length, 4oft. wide, and $36 \mathrm{ft}$. high, and fitted with five large penstocks or valves, which are raised or lowered by machinery.

The Low Level North will commence by a junction with the Western Drainage near Cremorne, and flow along the intended Chelsea Embankment to Pimlico, where its contents will be pumped up a height of $17 \frac{1}{2}$ feet into the remaining length, which will flow viâ the Thames Embankment to Abbey Mills. Its length, including branches, is about $12 \frac{1}{4}$ miles, and it varies in size from $6 \mathrm{ft}$. gin. to Ioft. 3 in. diameter. The area drained by it, including the Western Drainage, the sewage of which it receives, is $24 \frac{1}{2}$ square miles. This sewer is by far the most interesting on the north side, in consequence of the large works in connection with it. In the first place, it receives the drainage of the Isle of Dogs, in consequence of which, what was formerly little better than a marsh is now perfectly habitable; in the second place, it will pass along the two new embankments, viz., Chelsea and the Northern Thames; and in the third, its contents will be twice lifted by steam power, the lift at Pimlico being over I $7 \mathrm{ft}$., and that at Abbey Mills $36 \mathrm{ft}$. At Blackfriars Bridge, where it intercepts the Fleet, there will be a large penstock-chamber fitted with four penstocks and as many tide flaps, to prevent the return of the tide at high water. A large portion of this sewer, namely, that extending from Blackfriars to Abbey Mills, will be executed for the most part in tunnel.

The Northern Outfall Sewer, which receives the whole of the sewage on the north side of the Thames, is totally unlike any other portion of the Main Drainage system, being entirely above the ordinary level of the ground. The first length, from $B$ to $C$ (see plan), consists of a double line of sewers, each being $9 \mathrm{ft}$. by $\mathrm{gft}$. of the section shown in Fig. I running parallel to each other; at $\mathrm{C}$ it receives the contents of the Low Level, and from this point to the reservoirs at Barking it is of the section shown in Fig. 2, which is three parallel culverts $\mathrm{gft}$. by 9 ft. built upon a concrete foundation and covered by an earthen embankment, the top of which would serve as a road or railway. In its course to Barking it crosses the River Lea and

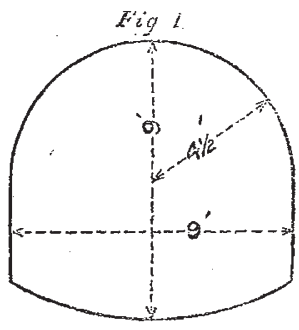
six streams, four railways, and ten roads. Fig. 3 gives a general idea of the method adopted for carrying the sewers over the streams, railways, \&c. It consists of three cast-iron culverts carried between four wrought-iron girders, the top being covered with cast-iron plates, which support the ballasting, roadway, \&c. ; the parapets are ornamented with cast-iron mouldings.

The contents of this sewer are received by the reservoirs. at Barking. These are about $9 \frac{7}{2}$ acres in extent; and $16 \frac{60}{4} \mathrm{ft}$. 


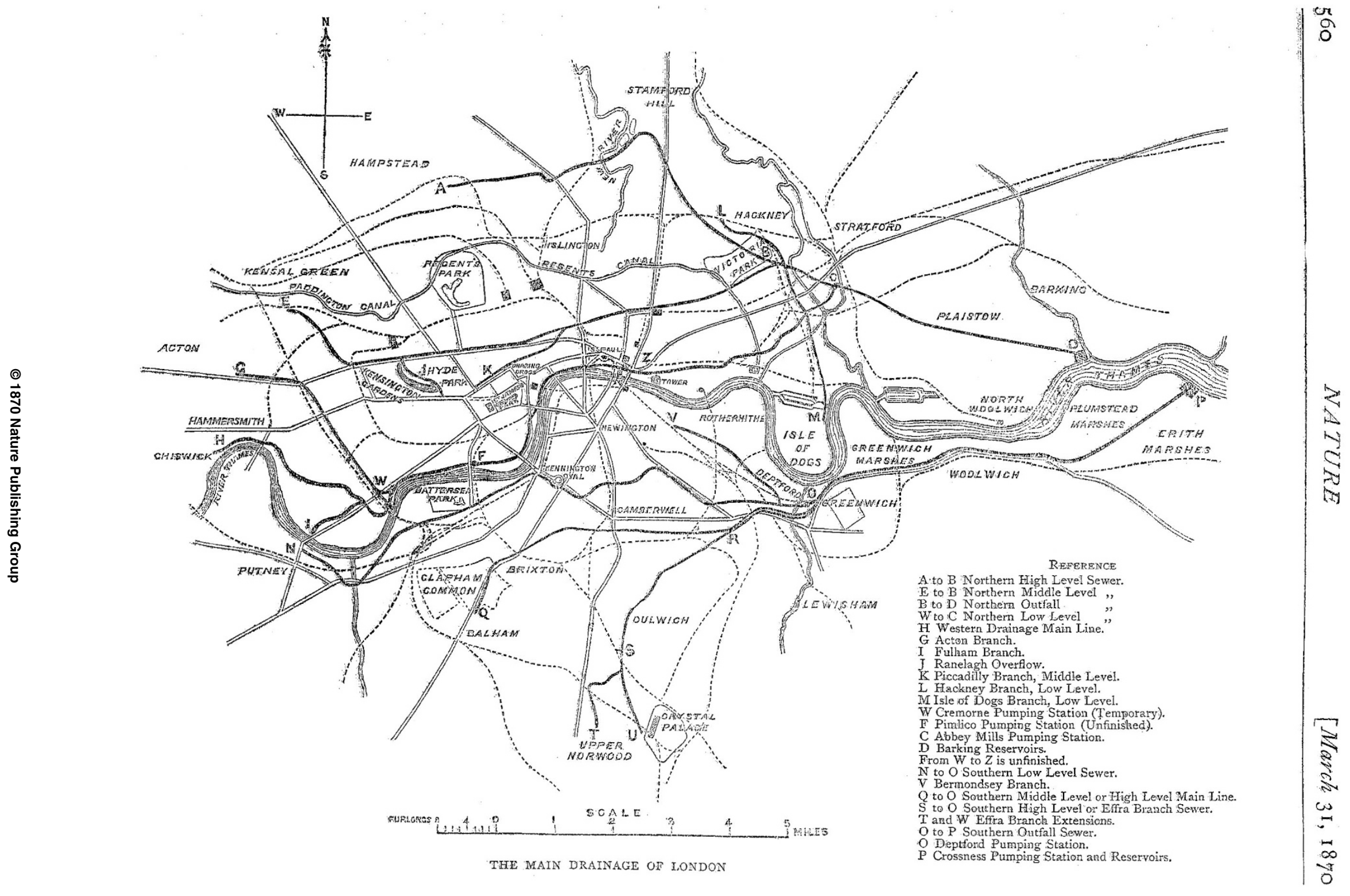


deep, covered in by brick arches, the floor being paved with stone. Attached to each is an outlet fitted with penstoclks, \&c. The Abbey Mills pumping station is a work of such magnitude and importance that but a scanty idea can be given, of it here: suffice it to say, that there are eight engines employed, of a gross power of I, I 4 O horsepower, which work sixteen double-acting pumps of $3 \mathrm{ft}$. io $\frac{1}{2}$ in. diameter and $4 \frac{1}{2} \mathrm{ft}$. stroke. The engines are supplied by sixteen boilers, each being $8 \mathrm{ft}$. diameter and 3oft. long. 'The engine and boilers, coal stores, \&c., are enclosed in a fine block of buildings beautifully decorated.

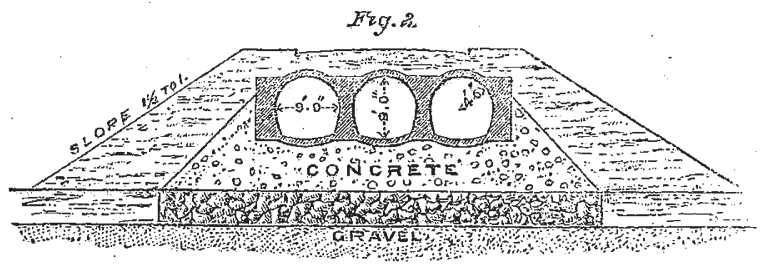

The Southern High Level, or Effra Branch Sewer, commences at Dulwich, and flows in a south-easterly direction to a junction with the Middle Level or High Level main line at New Cross. It is $4 \frac{1}{2}$ miles in length, $\frac{1}{4}$ mile of which is in tunnel. It varies in size from $7 \mathrm{ft}$. diameter to a form similar to one of the culverts in Fig. 2 , only the dimensions are roft. $6 \mathrm{in}$. by roft. $6 \mathrm{in}$.

The Southern Middle Level, or High Level main line, commences at Clapham, and flows under Deptford Creek to the Outfall Sewer. It, together with the High Level, drains an area of about 20 square miles. It is carried under Deptford Creek by four $3 \mathrm{ft}$. 6in. diameter iron pipes. Overfows for storm waters are provided, which discharge into the Creek, if necessary.

The Low Level Sewer South commences at Putney, and flows to Deptford pumping station, where its contents are pumped up a height of 18 feet, by four engines I25 horse-power each, into the Outfall Sewer. Its length is about 10 miles, and it drains an area of about 20 square miles, the greater portion of which is considerably below high-water mark. It varies in size from one culvert $4 \mathrm{ft}$. in diameter, to two, each $7 \mathrm{ft}$. by $7 \mathrm{ft}$. The soil in which it was executed was exceedingly treacherous in places, being greatly charged with water : in one case sufficient enginepower had to be emplojed to pump ten million gallons per day, in order to keep the works clear of water. The Bermondsey branch of this sewer is two miles in length,

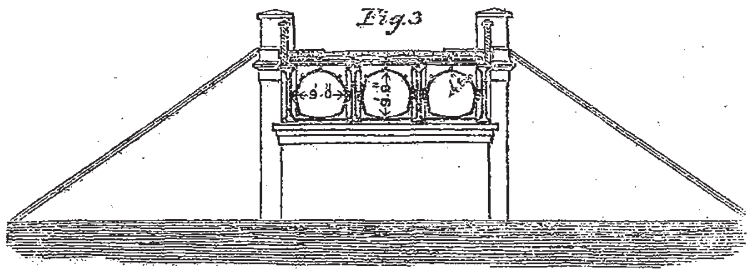

and from $5 \mathrm{ft}$. to $5 \mathrm{ft}$. $6 \mathrm{in}$. diameter. It joins the Low Level at High Street, Deptford.

The Southern Outfall Sewer, which receives the contents of the High, Middle, and Low Level sewers, flows from Deptford to the reservoirs at Crossness. Unlike the Northern Outfall, it is underground for its entire length. It is I Ift. 6in. diameter, and 73 miles in length. One mile of it was constructed in tunnel under the town of Woolwich. The outfall of this sewer is of such a level as to allow of the sewage being discharged at low water, but it will be pumped into the reservoirs, and there stored till high water.
The Crossness pumping station reservoirs are situated on the northern side of Erith Marshes at the point marked $P$ on the map. They extend over $6 \frac{1}{2}$ acres. The reservoirs are similar to those at Barking. There are four beam engines employed of 125 horse-power each, which drive eight pumps, each pump having four compound plungers. The engines are supplied by twelve Cornish boilers 3 oft. long and $8 \mathrm{ft}$. diameter. The ordinary amount of sewage to be lifted is about 60,000 gallons per minute, the lift varying from Ioft. to $30 \mathrm{ft}$., which necessitated a peculiar construction in the pumps. The sewage is delivered from the pumps into the reservoirs till high water, when it is discharged into the river. The foundations for the reservoirs, \&c., had to be surk $25 \mathrm{ft}$. below the surface, as the ground consists of peat and sand. On the top of the reservoirs are built the manager's, schoolmaster's, and labourers' cottages, coal stores, school, and workshops, the centre space being laid out as ornamental gardens, the whole forming quite a village of some hundred inhabitants.

\section{NOTES}

THE last number of the Proceedings of the Royal Society contains the names of the 53 candidates, from among whom, 15 will be selected by the council for election into the society. The list is a varied one, and there is as usual a large number of medical candidates- $2 \mathrm{I}$; Art and Literature being also represented. Here is the list :-William Baker, C.E., E. M. Barry, R.A., Rev. Francis Bashforth, B. D., B. E. Brodhurst, F.R.C.S., Samue1 Brown, P.I.A., James Brunlees, C.E., F. T. Buckland, M.R.C.S., G.W. Callender, F.R.C.S., CommanderW. Chimmo, R.N., F. Le G. Clark, F.R.C.S., Henry Dircks, Alex. Fleming, M.D., P. Le Neve Foster, Sir Charle Fox, C.E., William Froude, T. M. Goodeve, E. H. Greenhow, M.D., E. T. Higgins, M.R.C.S., Rev. Thomas Hincks, Charles Horne, Rev. A. Hume, LL.D., James Jago, M.D., W. S. Jevons, George Johnson, M.D., M. K. King, M.D., J. A. Langridge, C.E., N. S. Maskelyne, M. T. Masters, M.D., Major F. G. Mohtgomerie, R.E., Alfred Newton, Andrew Noble, Thomas Nunnely, F.R.C.S., E. L. Ormerod, M.D., Captain Sherard Osborn, R.N., Rev, Stephen Parkinson, B.D.; Captain R. M. Parsons, R.E., W. O. Priestly, M.D., C.B. Radcliffe, M.D., W. H. Ransom, M.D., E. J. Reed, C.B., W. J. Russell, Ph.D., R. H. Scott, John Shortt, M.D., Edward Thomas, C. F. Varley, C.E., G. F. Verdon, C.B., Augustus Voelcker, Ph.D., Viscount Walden, P.Z.S., G.C.Wallich, M.D., A. T. H. Waters, M.D., Samuel Wilks, M.D., Captain C. W. Wilson, R.E., and John Wood, F.R.C.S.

THe Pall Mall Gazette has very properly called public atten. tion to. Lord Kinnaird's imputation of dishonesty brought against the late Master of the Mint, the lamented Graham. The good old rule, de mortuis nil nisibonum, is one with which Lord Kinnaird does not seem to be acquainted ; it is charitable, indeed, to suppose that he sinned in ignorance. He probably also does not know that Graham was a far greater man than he, and that Graham's name will live long after Lord Kinnaird's has been forgotten.

ON Saturday the members of Working Men's Clubs visited the British Museum, under the guidance of Professor Owen and $\mathrm{Mr}$. Henry Woodward. Professor Owen explained the nature of the extinct animals. The next visit will be made to the National Gallery, under the guidance of Mr. Francis Turner Palgrave.

THE examinations for the gold and bronze medals offered as prizes for proficiency in Physical and Political Geography, by the Royal Geographical Society, were held on Monday last, 28 th inst. Forty-one schools had been invited to compete, ort of which number nineteen accepted, sending a total of fifty-urine 